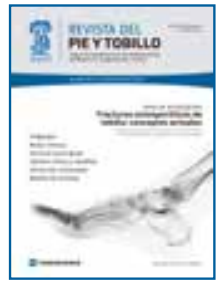

\title{
Editorial
}

\section{Nueva estructura para un nuevo tiempo}

\section{New organization for a new time}

Estimados compañeros:

En esta nueva etapa de la Revista del Pie y Tobillo (RPT) que tengo el honor de dirigir, os enumero las novedades que hemos implantado en la misma y que se pueden observar ya en este número.

Comité Editorial. Una de las quejas que más recibíamos de los autores que enviaban trabajos a la revista era la demora en recibir una respuesta positiva o negativa a los mismos. Para esto hemos decidido ampliar el Comité Editorial, contando con nuevos revisores y apostando por gente joven, pero con experiencia editorial y científica, sin olvidar a los compañeros que habían formado parte de la RPT y que seguirán colaborando con sus evaluaciones. También contamos con un importante Comité de Expertos para determinadas situaciones de controversia en la evaluación de los trabajos recibidos.

Compromiso. Es uno de los objetivos de esta nueva etapa el cumplimiento de los tiempos de respuesta a los autores, índice de calidad de cualquier revista científica.

Internacionalización. El español es la segunda lengua más hablada del mundo y nuestra revista no puede olvidar este importante aspecto. Así, hemos incorporado a nuestro comité a especialistas en pie y tobillo con conocimientos de nuestro idioma, especialmente de Latinoamérica, todos ellos con especial relación con la sociedad. Creemos firmemente que esto supone un salto cualitativo en la RPT y también una manera de publicitarnos en otros países. 
Nuevas normas editoriales. Hemos actualizado las normas editoriales adaptándolas a un modelo similar al de la revista de la Sociedad Española de Cirugía Ortopédica y Traumatología (SECOT) que, como todos saben, está indexada en PubMed. No perdemos de vista nuestro objetivo final, a largo plazo, de indexar nuestra publicación oficial, objetivo ambicioso pero posible.

Esperamos desde el Consejo de Redacción que estos cambios sean de vuestro agrado y os animo como siempre a participar con vuestros trabajos en este interesante proyecto científico que es toda la sociedad.

Sin más, os deseo unas felices fiestas y un buen año 2019.

Mario Herrera Pérez

Director adjunto de la Revista del Pie y Tobillo 